\title{
Trading of Emission Certificates for Climate Protection: Using Markets and Private Capital for Development
}

\author{
Rainer Durth ${ }^{*}$
}

The realisation that climate change is caused and can also be stopped by humankind gained increasing recognition in 2007. The magic threshold up to which an increase in the average global temperature is considered to be still tolerable is between $2^{\circ}$ and $3^{\circ}$ Celsius. If this threshold is exceeded, the consequences are significant and almost impossible to control. In order to avoid this, greenhouse gas emissions will have to be cut in half against 1990 emission levels over the next 40 years around the globe. To achieve this, the European Union set itself ambitious goals in early 2007.

It has resolved

- to reduce its carbon dioxide emissions by $20 \%$ against 1990 levels. If a successor to the Kyoto Protocol can be agreed upon, it even considers a reduction by $30 \%$;

- to improve energy efficiency in Europe by $20 \%$ percent by the year 2020; and

- to meet $20 \%$ of end-energy consumption in the EU with renewable energies by the year 2020 .

\section{Kyoto and the Consequences for Carbon Emissions}

What efforts are required to achieve this becomes clear when we look at the Kyoto Protocol of 1997 - though it did not enter force until 2005 - which for the first time called for a limitation and reduction of greenhouse gas emissions. Under the Protocol, the European Union had aimed for a reduction of $8 \%$ in 15 years, and it achieved this objective primarily because the carbon dioxide emissions in many EU accession countries in Eastern Europe were declining anyway after the collapse of socialism. Now, another $12 \%$ reduction of the carbon dioxide emissions of 1990 is being aimed for in only eight years. Again, the reduction may increase

* Head of Division, KfW Carbon Fund. 
up to $22 \%$ if a successor to the Kyoto Protocol materialises. This time, however, these reductions must be achieved without the "coincidental benefits". And after these cuts, further similar reductions must be achieved before 2050 .

These goals are set to be achieved in a twofold manner: first, via promotional programmes of the German Federal Government and legislation consistently targeted at reducing carbon dioxide emissions (established in the Meseberg decisions of the Federal Government); and second, through the revision and expansion of the European Emission Trading System (ETS) for carbon emissions.

What does the carbon dioxide emission trading scheme look like? The fundamental idea behind the market for certificates is relatively simple: climate change is said to be caused by the emission of specific gases. The most well-known of these gases, carbon dioxide $\left(\mathrm{CO}_{2}\right)$, is a product of all combustion processes. The impact of carbon dioxide on the Earth's climate is completely independent of who emits the $\mathrm{CO}_{2}$ and where it is emitted. In order to contain climate change, the emission of these gases must be reduced. The reduction requirements under the Kyoto Protocol, however, currently apply only to industrialised countries.

\section{Advantages of Trading in Certificates}

In order to keep the costs of reducing $\mathrm{CO}_{2}$ emissions as low as possible, the Kyoto Protocol permits a country to purchase carbon dioxide emission reductions in another country. To enable trading, a title of ownership of $\mathrm{CO}_{2}$ emission allowances was created in 1997. Purchasing a certificate allows the newly-entitled owner to emit an additional tonne of carbon dioxide, while selling a certificate obliges the seller to reduce emissions by one tonne. The ownership rights can be traded so that $\mathrm{CO}_{2}$ emissions are reduced where it is least expensive for all parties involved. Many countries break down the restrictions among their enterprises. In Europe, this is done for roughly half of European enterprises within the framework of the Emission Trading System.

Carbon dioxide emission reductions are usually least expensive where the relevant facilities do not just have to be converted but actually need to be erected. This is usually the case in developing and emerging countries, for which no cap on $\mathrm{CO}_{2}$ emissions has yet been set. However, the participation of these countries in the international market for certificates is highly desirable for two reasons: first, they can reduce carbon dioxide emissions at a particularly low cost; and second, they accrue development benefits from the quite significant international capital inflows. This is why the so-called "Clean Development Mechanism" (CDM) was created. Individual projects or programmes which advance a country's industrial and ecological development are evaluated to determine the quantity of $\mathrm{CO}_{2}$ reductions they will bring about. Certificates are issued for these reductions which the project owner can then sell.

An example of a typical project is a wind farm in India which generates urgently needed electricity using renewable energy, that is, without any emissions. The project owner can sell the certificates to a German energy provider and invest 
the proceeds in the next wind farm, which might then operate with even more advanced technology. Through this process, climate protection and development can be mutually reinforcing.

\subsection{How Are Ownership Rights Awarded?}

Ownership rights describe the possibilities for using scarce resources. The ownership rights which are the object of the market for certificates are pollution rights. They are an entitlement to emit carbon dioxide into the atmosphere and were only created under the Kyoto Protocol in 1997. The initiator at the time was the USA, which has been working with similar environmental concepts since the 1980s in order to reduce sulphur dioxide emissions at as low a cost as possible. In 2005, the Kyoto Protocol entered into force. For European enterprises, it went into effect with the introduction of the ETS, which also began operating in 2005. From an economic perspective, an unprecedented experiment has taken place over the past roughly ten years: an entirely new, rather abstract right of ownership was created in international negotiations, and it is now being traded in a novel, global market.

The new ownership title raises many exciting questions. How are the emissions capped in the industrialised countries? Under which rules are the ownership rights actually awarded to project owners in developing countries? Does emissions trading really promote the development of these countries? Another interesting aspect is the emerging market for trading the ownership rights. How is a price for carbon dioxide set? To what extent does the market function on its own; where does the market fail? Today, international financial markets are highly differentiated. How are the risks spread in the nascent market for certificates? Which of the otherwise customary financial derivatives are usable in this market? And what parallels are there to the commodity markets and their instruments?

\subsection{A Staggering Development - Annual Average Growth of $120 \%$ Since 2005}

The new market for $\mathrm{CO}_{2}$ certificates is very dynamic. Since the ETS was introduced in the European Union in 2005, it has grown by an average of some $120 \%$ annually (until 2009 and on US dollar basis). In 2008 it had a worldwide volume of USD 118 billion, nearly doubling its volume over the previous year. In only five years, the global carbon market has reached the volume of worldwide development assistance payments, which also posted a record year in 2008 (official development assistance in 2008 stood at USD 119 billion). Despite the current crisis, experts anticipate that the carbon markets will continue growing in 2009: an annual volume of USD 150 billion could be achieved within a few months.

Projects in emerging and developing countries currently account for roughly one-fifth of the new market. Revenue generated from the certificates, in turn, partly finances projects whose volume of investment is already roughly equal to 


\section{Carbon Market Development}

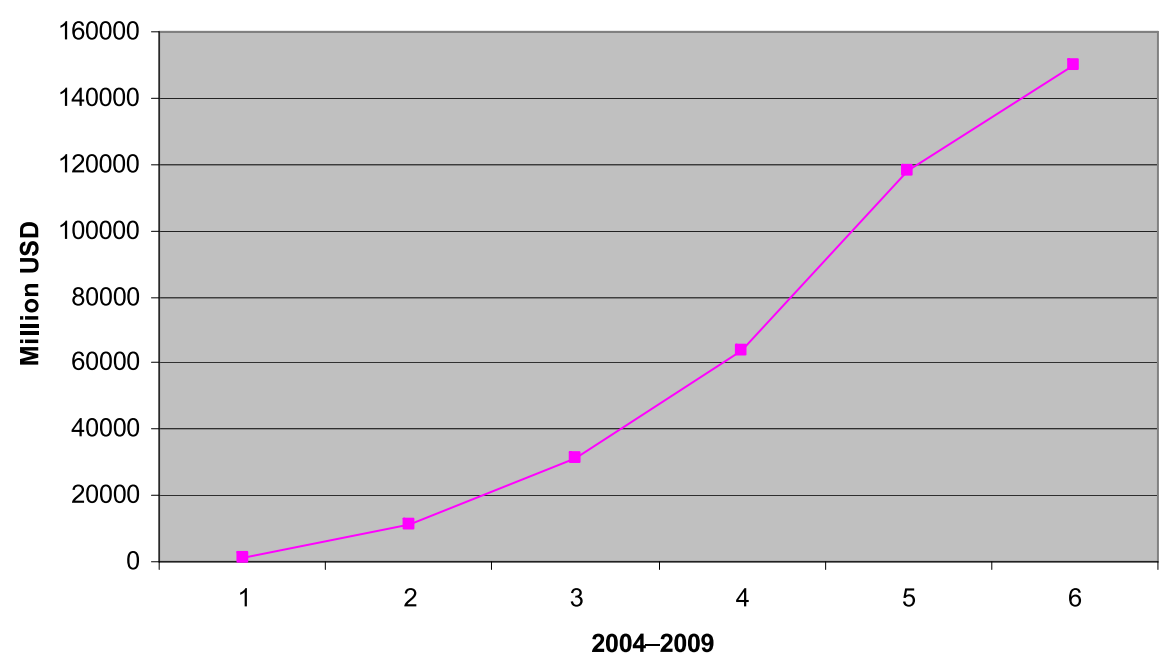

Fig. 1. Staggering growth of market volume - from 2004 to 2009 the global market for carbon emission certificates developed with great dynamism.

the official development assistance provided worldwide. According to expert estimates, by the year 2020 the market for climate protection projects in developing countries may have again increased tenfold. What is particularly intriguing from an economic point of view is the fact that the market can be used as an allocation mechanism, that is, as a mechanism for the large-scale allocation of financial resources, productive forces and materials, to set development processes in motion. The more successfully this can be done, the faster the market for certificates will grow and the more additional resources for development will be available.

Climate change is one of the greatest present-day challenges. By launching the international trade in emission certificates just over ten years ago, a worldwide economic-policy experiment was initiated - with an impressive history of success. Some qualifications also need to be made, however. This emerging market is not yet a perfectly competitive one: efficiency can be increased, thereby reducing the cost of climate protection policy. On the buyer side in particular, there are mostly small numbers of large buyers, such as states and energy supply companies. Information about the market is incomplete, uncertain and usually distributed unevenly among the individual market participants, and adjustments are always slow to be implemented. Moreover, given the uncertain future of the traded ownership rights after 2012, it is important to finalise a socalled "Post-Kyoto Agreement". 
Although growth is also expected for 2009, the current economic and financial crisis is having a crippling effect on the market for certificates. The uncertainty over how it will continue after 2012 and the reduced economic activity in industrialised countries are negatively impacting demand for CERs. At the same time, the supply of CERs is pre-established by the projects that were set up years ago and can only partially be adjusted in the short term. This leads to declining prices for CERs and, hence, less incentive to implement a climate protection project. Moreover, in the current environment of economic uncertainty, investors are perceivably more averse to risk. Financing a climate protection project today is much more difficult than just a year ago, particularly in developing countries, where risks are high. Combined, these factors have led to a reduction in the number of new climate protection projects than was originally expected; and there will be a reduced offer of certificates in the future than was originally expected.

\section{An Appropriately Engineered Emissions Trading Supports Development Policy}

Although the CDM was developed with a view to the developing countries, it must be said that it currently benefits primarily large emerging countries. Roughly $75 \%$ of the CER market is in China, India and Brazil, countries whose megacities benefit through their vast energy demand. This means that capital inflows under the CDM are highly concentrated, even more so than those generated by foreign direct investment. And it is precisely the smaller and poorer developing countries that have had little access to this market. Suitable project forms for these countries must urgently be developed; they should also reward improvements made in rural energy demand by issuing certificates. So-called programme-based approaches that enable a large number of small activities covering a large area hold promise for success in these countries.

From the point of view of development policy, the existing market inadequacies should be addressed in such a manner as to effectively facilitate developing countries' access to the rapidly growing market for certificates. The focus should lie on two aspects:

- Uncertainty and risk. Project investors need to have certainty about the expected capital inflows and possible financings. Down payments and guarantees of acceptance for developmentally desirable projects can be helpful in this regard.

- Transaction costs. Using the market for certificates requires extensive expertise and methods tailored to the needs of developing countries. In both cases, development cooperation can achieve much at a low cost. 


\section{Carbon Funds: Promoting Climate Protection Projects in Developing Countries and Access for Small and Medium- Sized Enterprises from Europe}

Investments in $\mathrm{CO}_{2}$ reductions must be made today. The market for certificates cannot fully unfold its potential unless the existing market inadequacies are effectively addressed. This is an objective pursued by the Carbon Fund of KfW Bankengruppe. The principle of the KfW Carbon Fund is simple. The Fund purchases internationally-recognised certificates from projects that improve energy efficiency or convert energy from renewable sources. In comparison with other funds, the share of certificates from projects in African or Latin American countries is particularly high. In order to enable small and medium-sized European enterprises in particular to access the market for certificates as buyers, KfW acts as a trustee of a buyers' pool in the international market.

In 2004 the KfW Carbon Fund started by focusing on developing the market for emission rights. Since then, the market has developed quite dynamically but, as described above, parts of the market are not yet functional. Now, important individual market segments in which market mechanisms fail must be effectively developed. This may be accomplished, for instance, by:

- developing specific project approaches which benefit the developing countries in particular;

- employing innovative financial products; or

- generating demand for "post-Kyoto certificates" which cannot be generated until after 2012 and for which no legally binding rules are yet in place.

As a promotional bank, KfW assumes a pioneer role, wherever possible together with other European promotional banks.

\section{Lessons from Financial and Commodity Markets for Development and Climate Protection Policy}

Market mechanisms still need to be harnessed more consistently for development policy measures and for an economically efficient climate protection policy. Here, the young market for certificates can learn much from the international financial and commodity markets. In the market for certificates, there will be an increasing number of new products which will be fraught with risks of their own and will require new hedging mechanisms, for instance hedges against price or climate risks. A wide range of services will therefore emerge around the market for certificates, ranging from specialised certificate brokers and consulting services for monitoring and reporting on avoided $\mathrm{CO}_{2}$ emissions, for example, to law firms specialising in contractual relations, usually based on common law, involved in the purchase of certificates. Soon the market for certificates will have shed its exotic character and will increasingly reach banks, project developers and development policymakers. 
In the future, a particular task for development economists will be to structure the markets and rights of disposal in such a way that they meet the specific needs of the frequently small and poor developing countries better than today. The main issue in the short term will revolve around how developing countries can guard against the consequences of climate change ("adaptation"). In the long term, the question will be: how can they integrate their economic potential with their support of international climate protection policy while pursuing their own development goals ("avoidance")? All along this path, new technologies will be developed and tested on a large scale, and they will have to be made available to developing countries and disseminated there ("technology transfer").

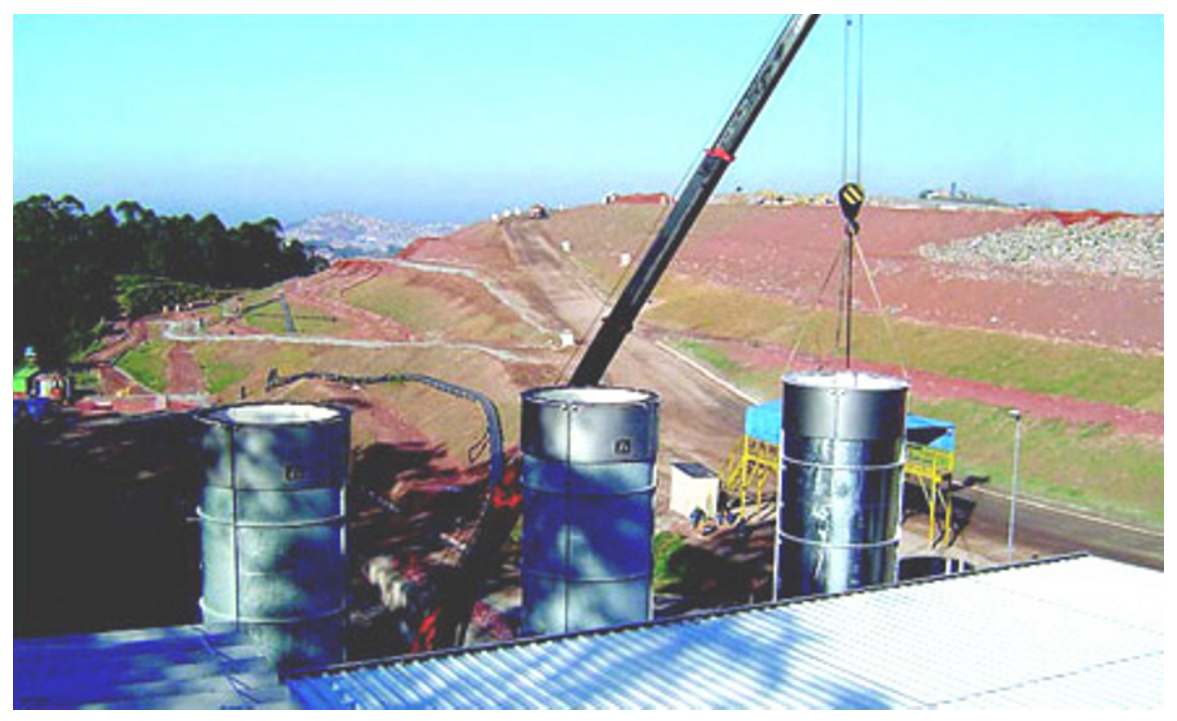

Fig. 2. Landfill in São João, São Paulo, Brazil. The fermenting of waste releases methane which is captured to protect the atmosphere. This facility was partly financed through emission certificates.

Open Access. This chapter is distributed under the terms of the Creative Commons Attribution Noncommercial License, which permits any noncommercial use, distribution, and reproduction in any medium, provided the original author(s) and source are credited. 